Corrigendum

\title{
Corrigendum to "Complete Chloroplast Genome Sequence of Justicia flava: Genome Comparative Analysis and Phylogenetic Relationships among Acanthaceae"
}

\author{
Samaila S. Yaradua $\mathbb{D}^{1,2}$ Dhafer A. Alzahrani $\mathbb{D}^{1}{ }^{1}$ Enas J. Albokhary $\mathbb{D}^{1},{ }^{1}$ Abidina Abba $\mathbb{D},{ }^{1}$ \\ and Abubakar Bello ${ }^{2}$ \\ ${ }^{1}$ Department of Biology, King Abdulaziz University, Jeddah, Saudi Arabia \\ ${ }^{2}$ Centre for Biodiversity and Conservation, Department of Biology, Umaru Musa Yaradua University, Katsina, Nigeria \\ Correspondence should be addressed to Samaila S. Yaradua; dryaradua@gmail.com \\ Received 16 April 2020; Accepted 21 April 2020; Published 18 July 2020 \\ Copyright (c) 2020 Samaila S. Yaradua et al. This is an open access article distributed under the Creative Commons Attribution \\ License, which permits unrestricted use, distribution, and reproduction in any medium, provided the original work is \\ properly cited.
}

In the article titled "Complete Chloroplast Genome Sequence of Justicia flava: Genome Comparative Analysis and Phylogenetic Relationships among Acanthaceae", the funding was omitted in error. The statement is shown below:

"This project was funded by the Deanship of Scientific Research (DSR), King Abdulaziz University, Jeddah, under grant no. D-119-130-1441. The authors, therefore, gratefully acknowledge DSR technical and financial support."

\section{References}

[1] S. S. Yaradua, D. A. Alzahrani, E. J. Albokhary, A. Abba, and A. Bello, "Complete chloroplast genome sequence of Justicia flava: genome comparative analysis and phylogenetic relationships among Acanthaceae," BioMed Research International, vol. 2019, Article ID 4370258, 17 pages, 2019. 